\title{
Scalp ulceration from a circumferential head dressing after craniotomy: Case report of an uncommon complication due to human error
}

\author{
Ashutosh Singhal BSc MD, Peter W Bray MD FRCSC, Mark Bernstein MD MHSc FRCSC
}

\begin{abstract}
A Singhal, PW Bray, M Bernstein. Scalp ulceration from a circumferential head dressing after craniotomy: Case report of an uncommon complication due to human error. Can J Plast Surg 2004;12(4):210-212.

The present paper describes a previously unpublished complication of the application of a circumferential head dressing after cranial neurosurgery. A 34-year-old woman developed a large area of skin necrosis on her forehead from a circumferential head dressing applied after the surgical removal of a colloid cyst. Neurological recovery was excellent but plastic surgical repair of her iatrogenic cosmetic injury was required.
\end{abstract}

Key Words: Head dressing; Scalp ulceration; Surgical complication; Surgical error

In many neurosurgical centres, after craniotomy, the patient's head is circumferentially wrapped with gauze or flannel bandages in an effort to keep the wound clean and to produce scalp incisional hemostasis by compression. Some believe this practice is associated with a decreased rate of subgaleal fluid collection, although, to our knowledge, this has not been formally studied. The practice has generally been regarded as benign, and we could find no reports in the literature describing any complication associated with circumferential head dressings. In the present report, we highlight an uncommon but significant complication of application of a head dressing applied too tightly, after a successful neurosurgical intervention.

\section{CASE PRESENTATION}

History and clinical examination

A 34-year-old woman was referred with an eight-week history of increasing headaches, worse in the morning, and associated with nausea and vomiting. On examination, she had bilateral papilledema. The remainder of the neurological examination was normal.
Une ulcération du cuir chevelu causée par un pansement circonférentiel de la tête après une craniotomie : Rapport de cas d'une complication inhabituelle causée par une erreur humaine

Le présent article décrit une complication jamais publiée auparavant, secondaire à l'application d'un pansement circonférentiel de la tête après une neurochirurgie crânienne. Une femme de 34 ans a développé une grande zone de nécrose cutanée sur le front après l'application d'un pansement circonférentiel de la tête suivant l'excision chirurgicale d'un kyste colloïde. Le rétablissement neurologique a été excellent, mais il a fallu procéder à une réparation par chirurgie plastique de la blessure iatrogène cosmétique.

\section{Neuroimaging}

Magnetic resonance imaging demonstrated a cystic mass in the third ventricle, in the region of the foramina of Monro (Figure 1). The mass was hyperintense on T1 and hypointense on T2, consistent with a colloid cyst. There was associated hydrocephalus.

\begin{abstract}
Operation
The patient underwent craniotomy for resection of the colloid cyst. She was positioned in four-point Sugita pin-fixation, and the scalp flap was constructed of three orthogonal incisions centred on the coronal suture and open inferiorly to respect the blood supply. Magnetic resonance imaging-based neuronavigation and evoked potentials monitoring were used. Microsurgical total resection of the colloid cyst via an interhemispheric transcallosal approach was carried out. A full turban-style head dressing was applied at the conclusion of the procedure starting with a gauze dressing, two large laparotomy pads, and then circumferential wrapping using first flannel and then Kling bandages.
\end{abstract}




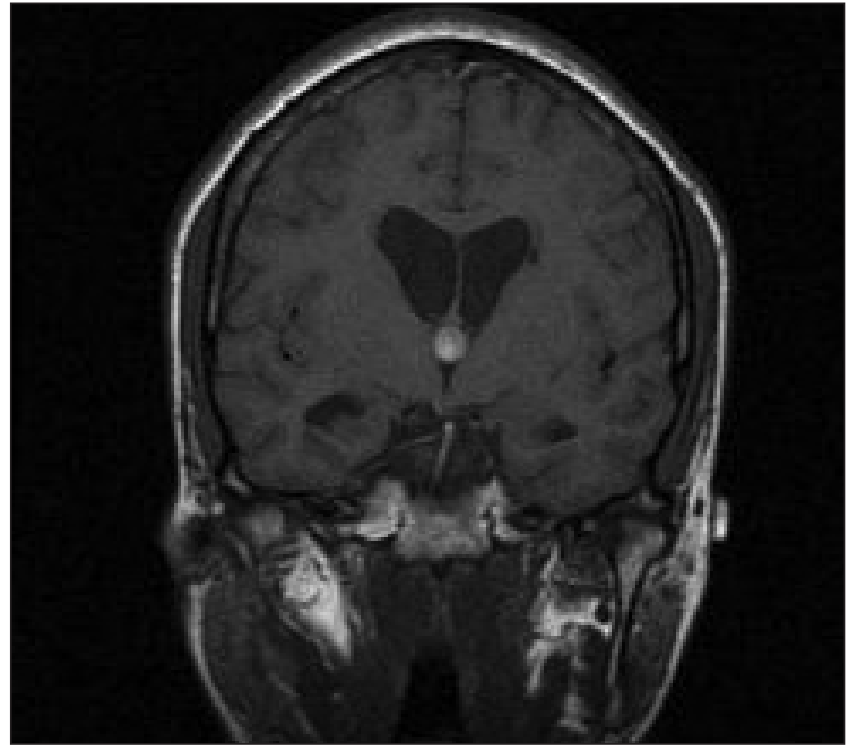

Figure 1) Coronal T1-weighted gadolinium-enhanced magnetic resonance image demonstrating the colloid cyst and hydrocephalus

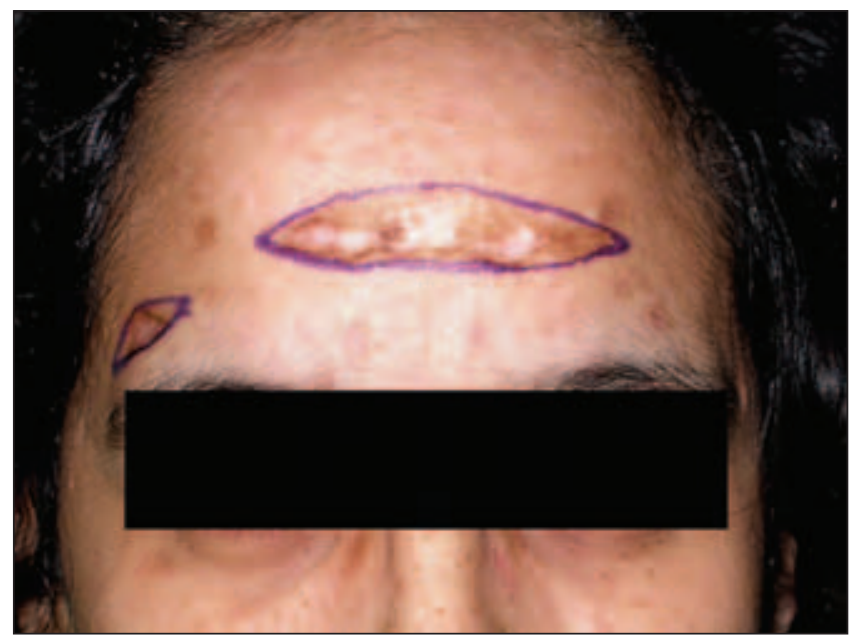

Figure 2) Photograph of the patient's forehead five months after her neurosurgical operation and immediately before plastic surgical correction. The patient gave consent for use of this photograph

\section{Postoperative course}

The patient was observed for one night in the neurosurgical stepdown unit, and then transferred to the general neurosurgical ward. There were no neurological deficits and postoperative recovery was unremarkable. She was discharged home on the third postoperative day; the head dressing was removed in the morning before she left. The patient reported some mild soreness of the forehead but there were no obvious skin abnormalities noted.

The patient noted that in the first few days after the head dressing was removed, her forehead appeared "burned" and was painful. Her family physician prescribed antibiotic cream. When the patient returned to the neurosurgeon's clinic six weeks postoperatively, the surgical incision was healing well. She had no headaches, and imaging revealed no residual cyst and well-decompressed ventricles.

However, two cosmetically important scars were noted. One scar was located in the right temporal region at the site of

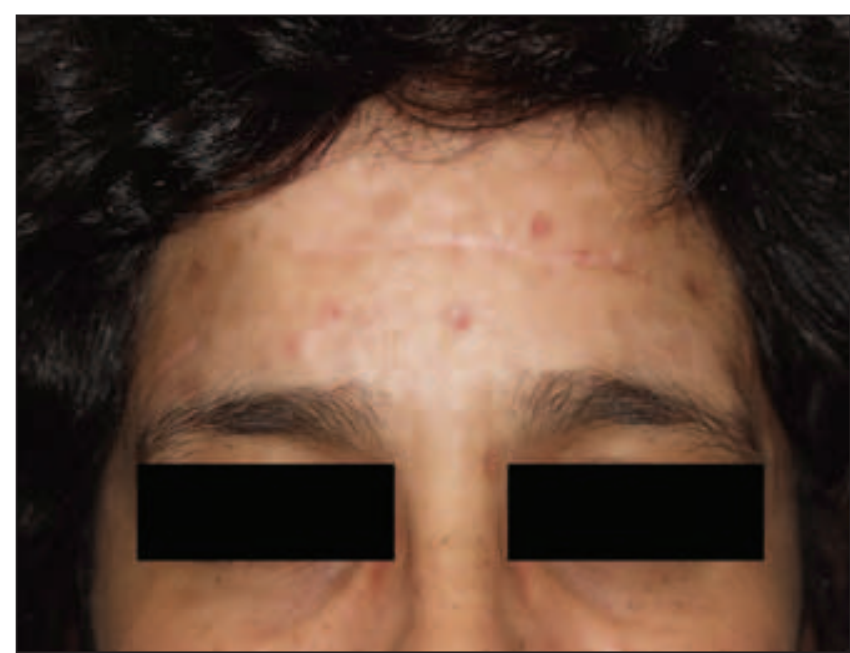

Figure 3) Photograph of the patient's forehead six months after plastic surgical repair of her forehead scar. The patient gave consent for the use of this photograph

one of the pins used for head fixation, and a second, larger scar was seen across the forehead, midway between the hairline and the eyebrows (Figure 2 ). This scar was irregular, approximately $6 \mathrm{~cm} \times 2 \mathrm{~cm}$ in dimension, depressed centrally and elevated peripherally with areas of hyper- and hypopigmentation. Its position was consistent with the transverse wrapping forming the lower border of the turban dressing.

The patient was informed that an error had been committed in that the head dressing had apparently been applied too tightly, and an apology was offered and accepted. She was referred to a plastic surgeon and, after a period of observation, there was little improvement in the cosmetic appearance. The patient underwent operative revision of the forehead scars five months after the initial neurosurgical procedure. A satisfactory cosmetic result was obtained and the patient was content six months following the scar revision (Figure 3).

\section{DISCUSSION}

We performed a search for any reported complications from the application of "full" head dressings, or "turban"-style head dressings. The publication database of the National Library of Medicine (PubMed) was searched using the terms "head dressing", "head dressing morbidity", "head dressing complications", "neurosurgery dressing", "head wrap", "head pressure dressing", "neurosurgery pressure dressing”, "turban dressing”, "turban”, "iatrogenic scalp ulcer", "iatrogenic scalp necrosis", "scalp breakdown”, "pressure sore neurosurgery”, "pressure sore scalp” and "pressure sore craniotomy".

We were unable to identify any reports documenting pressure injuries in the context of neurosurgical dressings. Ischemic necrosis has been described in the digits $(1,2)$ following the application of dressings possessing some degree of inherent elasticity. In one case of a bicoronal flap for access to midfacial fractures, an area of necrosis developed over a subgaleal suction drain (3). We doubt that ours is the first case ever of this complication in neurosurgery but we can say that it is the first such complication seen in the practice of the senior author (MB), whose experience includes approximately 3000 craniotomies.

In retrospect, the head dressing was likely too tight. Prevention of this problem may be accomplished in a number 
of ways: cessation of the use of circumferential head dressings; leaving a circumferential head dressing on for one day only, although this would not necessarily avoid the problem because irreversible skin injury can develop within $30 \mathrm{~min}$ to 60 min if perfusion is compromised by excessive pressure; careful training in the application of circumferential head dressings; and daily examination of the tightness of the head dressing and examination of the scalp for early signs of compromised skin viability.

\section{CONCLUSION}

We have documented a previously undescribed complication of the application of a post-surgical head dressing, which in this case occurred after successful craniotomy for resection of a colloid cyst of the third ventricle. This problem was due to a human error and should serve to remind us that beside focusing on the 'big jobs' in the highly technical and demanding surgical specialties, we must attend just as rigorously to the 'smaller details' to avoid complications for our patients.

\section{REFERENCES}

1. Ersek RA. Ischemic necrosis and elastic net bandages. Tex Med 1982;78:47-9.

2. Yaffe B, Shafir R. Complication with the elastic tubed net bandage. Orthop Rev 1986;15:553-4.

3. Barnard NA. Pressure necrosis of a bicoronal flap. Ann R Coll Surg Engl 1989;71:353. 